\title{
Anatomy of the Liver (A05.8.01.001). Worldwide Review, 2019. New Findings, Concepts and Definitions Support a Division of the Liver into Seven Portal Segments
}

\author{
Anatomía del Hígado (A05.8.01.001). Revisión Mundial, 2019. Nuevos Hallazgos, Conceptos \\ y Definiciones Respaldan una División del Hígado en Siete Segmentos Portales
}

\author{
César Augusto Durand López
}

DURAND, L. C. A. Anatomy of the liver (A05.8.01.001). Worldwide Review, 2019. New findings, concepts and definitions support a division of the liver into seven portal segments. Int. J. Morphol., 37(3):1179-1186, 2019.

SUMMARY: Due to a lack of consensus on the description of the human liver anatomy, we decided to explore different researches worldwide. Studies are focused on the hepatic vascularization. The results obtained through serial dissections in embryos, fetuses and adults have contributed to new definitions. Researchers around the world have agreed on finding the bases to propose a liver segmentation with seven portal segments.

KEY WORDS: Liver anatomy; Seven portal segments.

\section{INTRODUCTION}

Walaeus (1640), Glisson (1681), Rex (1888), Cantlie (1898), McIndoe \& Counseller (1927), Hortsjö (1948), Healey \& Schroy (1953), Couinaud (1954), Pintado Luna \& Durand (1978), Ken Takasaki (1986) and Steven Strasberg (2000) promoted the studies on liver anatomy, whose results are the base of our research. Research on liver vascularization has made advances. Embryological, physiological, radiological, surgical studies and anatomical dissections lead to new concepts.

Soyer (1993), Botero \& Strasberg (1998), Ishibashi et al. (2001), Fischer et al. (2002), Rieker et al. (2003), Rutkauskas et al. (2006), Fasel et al. (2010), Fasel \& Schenk (2013), Vinnakota \& Jayasree (2013), Bismuth $(2013,2014)$ and Castorina (2014) pointed out the need for a consensus on hepatic terminology. This is what has been done in the last 5 years.

\section{MATERIAL AND METHOD}

For the development of this work, a review of the literature was carried out, without excluding the date of publication, with the inclusion of references in the study of the segmental anatomy of the liver. Finally, a total of 59 texts were included.

\section{RESULTS AND DISCUSSION}

Embryological development of the liver. Champetier et al. (1989), Couinaud (1999), Abdalla et al. (2002), Germain et al. (2014) contributed to the study of the embryological evolution of the liver. Hikspoors et al. (2017a) stated: "Starting at 5 weeks, the portal (right vitelline vein), portal sinus and umbilical veins (intrahepatic portion) sprouted portal vein branches that, at 6.5 weeks, have been pruned to 3 main branches inside the right hemi-liver, whereas all (>10) persisted in the left hemi-liver. At 6 weeks, 3-4 main hepatic vein outlets drained into the inferior cava vein. Two small portal branches emerged from the portal sinus at week 5 to supply the caudate lobe; one week later, the inferior vena cava (ICV) gives off the venousdrainage from the caudate lobe. The square lobe receives the portal branches from the portal sinus and from the intrahepatic portion of the umbilical vein during week 6 . At 8 weeks, the portal diameter is $10-15 \%$ of the umbilical vein. The portal branches come out in a monopodial way; on the left side, the branches are born spirally and are thin. We observed that the monopodial branching pattern of the umbilical vein is, however, clearly at odds with the supposedly dichotomous branching pattern of the portal vein that underlies Couinaud's segmental liver anatomy. The bile ducts are canalized and the segmental arteries appear at week 10". They described three portal segments on the right side of the liver and plotted seven portal segments for the entire liver (Fig. 1). 


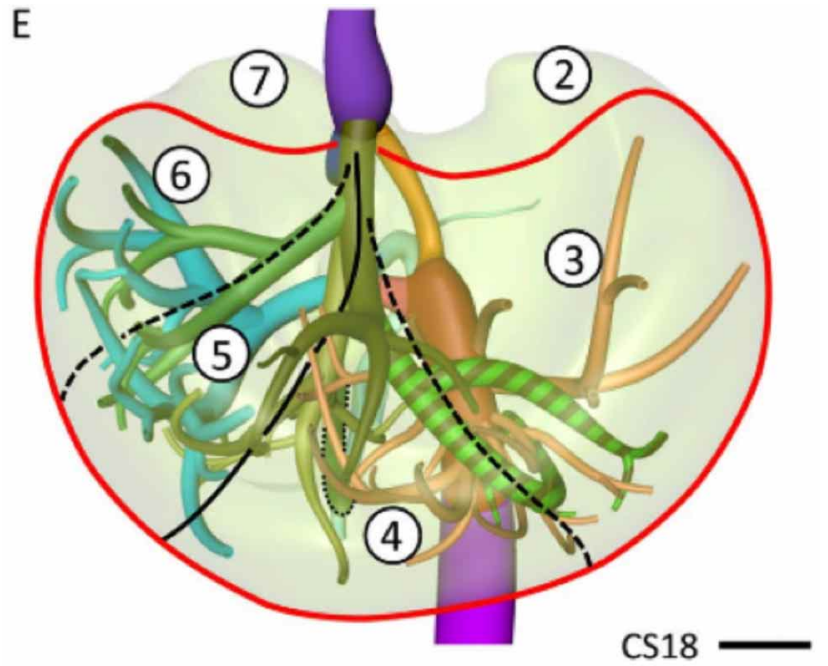

Fig. 1- Original figure of Hikspoors et al., showing the findings of their research in human embryonic livers: seven portal segments. (With permission).

External morphology of the liver. Marcos et al. (2000), Chhabra et al. (2014), Mitidieri \& Loccisano (2014), Patil et al. (2014), Joshi \& Chavan (2017), Sakamoto et al. (2017), Mehare et al. (2017) and Vernon \& Kasi (2019) have done studies on the superficial anatomy of the liver. Durand-López et al. (2018) insisted on the correct use of the word "lobe" when referring to the bulges delimited by ligaments or vascular elements to describe the liver (A05.8.01.001, International anatomical terminology) externally. He uses the term "part of the liver" to describe the vascular territory irrigated by the right or left portal branch. The external description of the liver has not presented novelties.

Porta hepatis (A05.8.01.016). Kawarada et al. (2000) informed: "All the variations in the bile ducts and vessels occur in the plate system (Porta hepatis)". Kelly et al. (2017) and Durand-López et al. (2018) described: The entrance door to the liver, the lower hilum, is a parenchymal channel formed by each and every one of the seven portal segments, which arrive here to receive their vascular pedicle and drain their bile production; it is completely covered by peritoneum. The Porta hepatis is centrally located in the middle third of the visceral surface; it has an "L" shape rotated ninety degrees to the left; it presents a transverse part, another anterior part, and they form a 90-degree angle of anterior medial sinus; the hepatic portal vein is divided here into right (A12.3.12.002) and left (A12.3.12.005) branches; the hepatic artery proper is divided into right (A12.3.12.030) and left (A12.3.12.035) branches; the common hepatic duct is formed by the union of the right hepatic (A05.8.01.062) and the left hepatic (A05.8.01.065); these branches form the first vascular division; then, on the edge of this parenchymal channel, these two "primary branches" emit seven terminal secondary branches, forming seven vascular pedicles for seven portal segments.

Hepatic portal vein (A12.3.12.001). Fasel (2008), Majno et al. (2014), Kimura et al. (2015), Sureka et al. (2015), DurandLópez et al. (2016, 2017, 2018) contributed to the study of the hepatic portal vein as it follows: the left portal branch presents a transverse part (A12.3.12.006) of 3-4 cm long and $12 \mathrm{~mm}$ of diameter; it derives from the embryonic portal sinus and emits branches for segment $\mathrm{I}$ in $100 \%$, segment $\mathrm{V}$ in $21 \%$ of cases and subsegmental branches for segment IV (square lobe); and another umbilical part (A12.3.12.008) of 1-2 cm long and $10 \mathrm{~mm}$ of diameter (it derives from the umbilical vein); both form a 90-degree angle of anterior medial sinus. Segment I (A05.8.01.044) receives a branch (2 $\mathrm{mm}$ of diameter) from the left portal branch and a subsegmental branch from the right portal branch in $60 \%$ or from the hepatic portal vein in 5\%; segment II (A05.8.01.039) receives a branch from the left portal angle (4 $\mathrm{mm}$ of diameter) that forms a 135-degree angle of posterior sinus with the transverse part of the left portal branch. Segment III (A05.8.01.040) receives a segmental branch from the left portal ( $6 \mathrm{~mm}$ of diameter) and two or three subsegmental branches that arise to the left of the terminal bulb of the umbilical part. Segment IV (A05.8.01.042) receives a segmental branch $(6 \mathrm{~mm})$ that arises to the right of the terminal bulb of the umbilical part of the left portal branch; in addition, there are two or three subsegmental branches that emerge from the right of the aforementioned bulb or from the upper edge of the transverse part of the left portal branch. The branch for segment V (10 mm of diameter) arises from the left portal branch in $21 \%$ of cases [Iqbal et al. (2017), reported $20-35 \%$ of these cases]; it emerges from the right portal branch in $79 \%$; the branch for segment $\mathrm{V}$, after deepening $2 \mathrm{~cm}$ in its segmental parenchyma, gives anterior, lateral, posterior and medial branches which encompass the parenchyma between the right portal fissure (A05.8.01.036) and the main portal fissure (A05.8.01.035) from the inferior borderof the liver (A05.8.01.024) to the inferior vena cava (A12.3.09.001). The branch for segment $\mathrm{V}$ is the only one existing for the right medial division (A05.8.01.046) of the liver. The right portal branch (1-3 cm long and $16 \mathrm{~mm}$ of diameter) emits the branch for segment $\mathrm{V}$ (A05.8.01.047) in 79\% of cases. The right portal branch ends up bifurcating into an anterior lateral branch (6 $\mathrm{mm}$ ) for segment VI (A05.8.01.050), and another posterior lateral (8 mm) for segment VII (A05.8.01.051) (Durand-López, 2016; Hikspoors et al., 2017b); all this happens inside the Porta hepatis (Fig. 2).

The portal vein and its branches attract the arterial and biliary duct to form seven portal pedicles for seven portal segments (Durand-López, 2016; Hikspoors et al. 2017a,b). Iqbal et al. (2017) reports the trifurcation of the portal vein when entering the liver. 


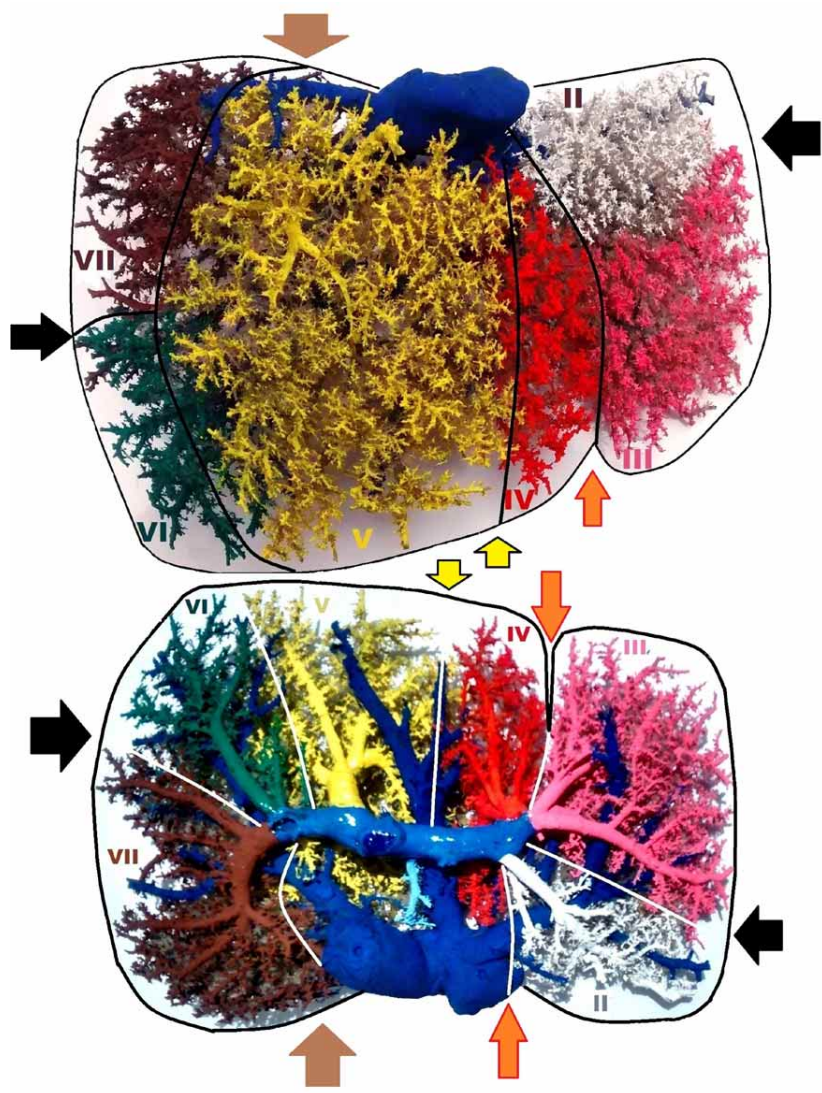

Fig. 2. Acrylics of the liver, diaphragmatic surface: upper figure; Visceral surface: lower figure. We see the primary branches (blue) of the portal vein (left and right) giving the secondary branches (segmental and terminal) in the visceral surface. For sSegment I in light blue, II in white, III in pink, IV in orange, V in yellow. Note, note that branch $\mathrm{V}$ gives anterior, lateral, posterior and medial tertiary branches that are distributed between segment IV to the left and segments VI-VII to the right, it is the only branch for the right medial "division" of the liver, there is no segment VIII; Segment VI in green and segment VII in brown. The diaphragmatic surface shows the same colors. Orange arrows point to the umbilical portal fissure, yellow arrows point to the main portal fissure, brown arrows point to the right portal fissure, and black arrows point to the horizontal fissures. Note that the left hepatic vein has an intrasegmental course; the umbilical fissure does not contain the left hepatic vein.

Arterial irrigation of the liver. Bianchi et al. (2014), Rachanee Chanasong (2014), Dandekar et al. (2015), Yan et al. (2015), Durand-López (2016) and Alghamdi et al. (2017) found: Arterial irrigation comes from the hepatic artery proper in $70 \%$ of cases; from the hepatic artery proper and a branch of left gastric artery (A12.2.12.013) in $25 \%$, from the hepatic artery proper plus a branch from left gastric artery plus a branch from superior mesenteric artery (A12.2.12.053) in $3 \%$, and from the hepatic artery proper and a branch from superior mesenteric artery in $2 \%$. The hepatic artery proper is divided into left and right branches; the left branch is short and less voluminous than the right branch. When the hepatic artery proper irrigates the liver, segment I receives a segmental artery from the left hepatic in $43 \%$, from right hepatic in $23 \%$, from both branches in $34 \%$. Segment II receives a branch from the left hepatic in $100 \%$. Segment III receives a branch from the left hepatic in $100 \%$. Segment IV receives a branch from the left hepatic in $71 \%$ or from the right hepatic in $29 \%$. Segment $V$ receives a branch from the right hepatic in $99.5 \%$ or from the left hepatic in $0.5 \%$. Segment VI receives a branch from the right hepatic in $100 \%$. Segment VII receives a branch from the right hepatic in $100 \%$. When right and left branches are born, they locate in front of the left portal vein. The left branch is located in front of and below the transverse part of left portal branch in $80 \%$ of cases. The left branch gives a secondary branch backwards for segment I; when reaching the angle of the left portal branch, a left posterior lateral branch is located above the portal angle for segment II; then, medially placed under the umbilical part of the left portal branch, it gives the branches for segment IV and segment III; the latter passes below the umbilical part of the left portal branch on the way to its segmental pedicle; the branch for segment IV is placed on the medial border of the umbilical part of the left portal branch. Arterial branches for posterior segments run above the portal vein branches, and for anterior segments they run below the portal vein branches.

Ibukuro et al. (2016) described the vascular relationships between the hepatic vessels (portal veins and arteries) with adjacent structures through the ligaments that support the liver.

Biliary drainage of the liver. Bret et al. (1988), Couinaud (1999), Kawarada et al. and Durand-López (2016, 2017, 2018) described: The segmental biliary branches accompany the arterial and venous portals until they form the left and right hepatic ducts; these are located above the primary portal venous branches, and when they join, they do so in front of and to the right of the portal vein at the Porta hepatis. It is observed that two segmental ducts, either on the right or left side, join in a common trunk, which, linked to the third or fourth bile duct of the corresponding portion, form the hepatic duct, either right or left. Generally, bile ducts I, II, III and IV constitute the left hepatic duct, and segmental ducts V, VI and VII form the right hepatic duct. This confluence is more constant on the left side. Segment I drains into the left hepatic duct (70\% of cases), into the right duct $(7 \%)$ or into both ducts ( $23 \%$ ); the segments II-III trunk drains into the left duct in $76 \%$ of cases, and the segments III-IV trunk drains into the left duct in $24 \%$. The segments VI-VII trunk, on the right side, flows into the left hepatic duct in $21 \%$ of cases, one centimeter from the junction of both hepatic ducts; in these latter cases, the segmental duct $\mathrm{V}$ forms the right hepatic duct. 
Vellar (2001) reported: "The venous drainage at the bifurcation of the common hepatic duct has been shown to enter the segment I and segment IV directly. This suggests that a hilar cholangiocarcinoma may metastasize to these segments, and perhaps this partly explains the significantly better long-term results when the caudate lobe and segment IV are resected en bloc with the cholangiocarcinoma as part of a modern radical surgery for this condition".

Portal fissures. Durand-López et al. $(2017,2018)$ contributed to the knowledge on hepatic fissures: The seven segmental branches of the portal vein are terminal, that is, they do not have anastomosis; the same happens with the arterial and biliary branches. This lack of anastomosis causes planes of separation among portal segments (fissures). There are three vertical and three horizontal fissures; the verticals are: 1) Umbilical portal fissure (A05.8.01.034), marked on the diaphragmatic surface of the liver by the hepatic insertion of the falciform ligament; it is tilted 50 degrees to the left in relation to the sagittal plane of the liver; it does not contain the left hepatic vein, however, it contains from the front to the back side: the round ligament of the liver, the umbilical part of the left portal branch, and the venous ligament in the parenchymal groove that forms its lower edge; it separates segments II-III from segment IV on the diaphragmatic surface, and separates segment III from segment IV in the front side and segment I from segment II at the back of the visceral surface. 2) Main portal fissure separates segment IV from segment V; it separates the right part from the left part of the liver in $79 \%$ of cases (when the portal branch for segment $\mathrm{V}$ is born from the right portal branch); the plane of this fissure inclines 30 degrees to the left in relation to the sagittal plane of the liver, containing the intermediate hepatic vein; its trajectory on the diaphragmatic surface of the liver goes from the fossa for gallbladder (A05.8.01.013) to the left edge of the inferior vena cava (A12.3.09.001) almost straight. The inferior border of this fissure is located on the bed of the gallbladder in the front side, and on the upper face of segment I at the back side. 3) The right portal fissure separates segment V from segments VI-VII; the fissure plane inclines 60 degrees to the right in relation to the sagittal plane of the liver; it contains the right hepatic vein, the right middle hepatic vein $(5 \%)$ and the right lower hepatic vein $(61 \%)$; its trajectory on the diaphragmatic surface of the liver starts from an intermediate point between the right edge of the gallbladder and the right angle of the liver to the right edge of the inferior vena cava, describing a wide curve of right convexity. This fissure separates the right hepatic part from the left part in $21 \%$ of cases; this happens when the segmental branch $\mathrm{V}$ emerges from the left portal branch, causing the $\mathrm{V}$ segment to belong to the left part of the liver, forming a small right part and another larger left part.
Vertical portal fissures divide the liver into four divisions. The main portal fissure divides the liver into right and left parts; the left part is divided by the umbilical fissure in a left lateral division (it contains portal segments II and III) and another left medial division (it contains portal segment IV); the right part is divided by the right portal fissure in a right medial division (it contains the portal segment $\mathrm{V}$ ) and another right lateral division (it contains the portal segments VI and VII).

The planes of the smallest horizontal fissures are located between segments II and III, between the upper face of segment I and the lower face of the posterior half of segments IV and V, and between segment VI and VII; they do not have vascular content.

Portal segments. Durand-López et al. (2017, 2018) defined: A portal segment is a portion of hepatic parenchyma with the following characteristics: 1) It is irrigated by a terminal branch of the hepatic portal vein, a terminal branch of the hepatic artery proper and / or its replacement, and drained by a segmental bile duct. 2) The absence of portal venous and arterial anastomoses among segments causes planes of separation between them (fissures). 3) Each and every segment forms the parenchymal channel of the Porta hepatis (inferior hepatic hilum), where they receive their segmental vascular pedicles; these are the three characteristics that define a liver portal segment.

Durand-López (2016) and Hikspoors et al. (2017a,b) reported on the birth of the segmental portal branches in a monopodic way and agreed on the number of these destined for seven segments. Hikspoors et al. $(2017 \mathrm{a}, \mathrm{b})$ did his research on embryos and fetuses while Durand did his research on fetuses, children and adults. Durand concludes in presenting this liver segmentation based on his definition of portal segment: Segmental account starts with the left portal branch; it gives off the segment I (posterior segment) branch, segment II (left lateral segment) branch, segment III (left anterior lateral segment) branch, segment IV (left medial segment) branch, segment $\mathrm{V}$ (right medial segment) branch that emerges from right portal branch in $79 \%$ of cases or from left portal branch in $21 \%$; right portal branch gives off segment VI (right anterior lateral segment) branch and segment VII (right posterior lateral segment) branch.

Hepatic veins, venous drainage of the liver (A12.3.09.005). Kalayc1 et al. (2014), Shilal \& Tuli (2015), Li et al. (2016), Zheng et al. (2017) and Durand-López (2018) contributed to the study of venous drainage of the liver: The hepatic veins drain into the inferior vena cava; we describe them in two groups: 
Hepatic veins, upper group. The right hepatic vein, the intermediate hepatic vein and the left hepatic vein belong to the upper group. The right hepatic vein is located $3 \mathrm{~cm}$ deep inside the right portal fissure; it reaches $20 \mathrm{~mm}$ of diameter and receives the drainage of segments V, VI and VII; the tributaries of segments VI and VII are larger than those of segment $\mathrm{V}$. The intermediate hepatic vein is located $4 \mathrm{~cm}$ deep inside the main fissure, reaching $20 \mathrm{~mm}$ of diameter; it receives the drainage of segments IV and V; tributaries of segment $\mathrm{V}$ are larger than those of segment IV; it receives the left hepatic vein in $97 \%$ of cases, forming a short $(1-2 \mathrm{~cm})$ common trunk that empties into the inferior vena cava; in $3 \%$, it flows directly into the inferior vena cava. The left hepatic vein does not occupy the umbilical fissure; it has an intrasegmental route; it reaches $16 \mathrm{~mm}$ of diameter; it drains segments III, II and IV; the left hepatic vein presents three types of formation and two forms of drainage; the first type of formation ( $80 \%$ of cases) is when it is born in the center of segment III, receives tributaries, enters segment II, forms a medial concavity curve receiving more tributaries and finally empties; the second type of formation (20\%) is when segments III and II offer a vein, each one, to form the left hepatic vein; the third type of formation is a variant of any of the previous two, which presents the opening of the fissure vein draining the back of segment IV; this vein is located in the posterior third of the umbilical fissure and becomes the last affluent of the left hepatic vein in $28 \%$ of cases. The drainage takes place in the inferior vena cava (3\% of cases) or in the intermediate hepatic vein ( $97 \%$ of cases).

Table I. Volumetric data for Couinaud's segments and venous drainage areas.

\begin{tabular}{|c|c|c|}
\hline Parts of the liver & Volume (mL) & $\begin{array}{ll}\text { vs. } & \text { TLV (\%) }\end{array}$ \\
\hline Total Liver Volume & $1138.0 \pm 208.8$ & 100 \\
\hline Left liver & $377.0 \pm 81.6$ & $33.2 \pm 4.7$ \\
\hline Right liver & $717.1 \pm 144.4$ & $63.0 \pm 5.1$ \\
\hline
\end{tabular}

Table II. Segmental volume (mL) vs. TLV (\%).

\begin{tabular}{lrr}
\hline Segment I & $89.3 \pm 46.5$ & $7.6 \pm 3.3$ \\
Segment II & $94.1 \pm 35.0$ & $8.3 \pm 3.0$ \\
Segment III & $112.6 \pm 38.8$ & $10.0 \pm 3.2$ \\
Segment IV & $128.6 \pm 37.7$ & $11.3 \pm 2.8$ \\
Segment V & $130.2 \pm 53.1$ & $11.5 \pm 4.7$ \\
Segment VI & $137.9 \pm 63.7$ & $12.1 \pm 4.8$ \\
Segment VII & $167.7 \pm 75.0$ & $14.6 \pm 5.6$ \\
Segment VIII & $269.3 \pm 78.8$ & $23.8 \pm 5.6$ \\
\hline
\end{tabular}

Table III. Venous drainage areas.

\begin{tabular}{lrr}
\hline Venous drainage area & \multicolumn{1}{c}{ Volume (mL) vs. TLV (\%) } \\
\hline Left hepatic vein (LHV) & $234.2 \pm 61.6$ & $20.7 \pm 4$ \\
Intermediate hepatic vein (IHV) & $369.3 \pm 96.6$ & $32.7 \pm 7$ \\
Right hepatic vein (RHV) & $456.7 \pm 188.1$ & $39.6 \pm 12$ \\
Middle right hepatic vein & $88.4 \pm 53.7$ & $8.0 \pm 4$ \\
Inferior right hepatic vein & $117.3 \pm 75.6$ & $10.6 \pm 6$ \\
Left hepatic vein region & & \\
\hline
\end{tabular}

Hepatic veins, lower group. The right middle hepatic vein (5\% of cases) and / or the right inferior hepatic vein (61\% of cases) are inside the right portal fissure; the latter reaches up to $20 \mathrm{~mm}$ of diameter, draining segments V, VI and VII. Segment I drains directly into the inferior vena cava through a variable number of veins.

Tani et al. (2016) reported the volumes of irrigation and venous drainage of the liver and expressed them in $\mathrm{mL}$ and as a percentage of the total liver volume (TLV) (Tables I, II, and III):

"The left superficial vein (LSV) and the umbilical fissure vein (UFV) were observed in all subjects, with a significant diameter $(>3 \mathrm{~mm})$ for each venous tributary observed on CT imaging in 46 and 96 of the 100 patients, respectively. The UFV was found to drain into LHV in the majority of cases $(87.2 \%)$. However, the UFV was occasionally seen draining into IHV $(7.3 \%)$. LSV drains segment II, and the UFV drains both segments III and IV. LSV accounted for a mean proportion of $22.9 \%$ of the drainage of segment II, and the UFV accounted for a mean proportion of $18.5 \%$ of the drainage of the medial part of segment III and $23.9 \%$ of the lateral part of segment IV. The majority of the volume of segments II and III were drained by the main trunk of LHV. Of note, a mean proportion of $76.1 \%$ of segment IV was observed draining into the IHV, with the remaining $23.9 \%$ of segment IV draining into LHV".

New proposals. Durand-López (2018) proposed this "liver anatomy and surgical resections" (Table IV).

\section{CONCLUSIONS}

Advances have been made in research of embryological development as well as in the exhaustive description of vascularization of the liver. This has originated new anatomical concepts, some coinciding, such as the number of portal segmental pedicles (Durand-López, 2016; Hikspoors et al., 2017a,b) that lead to propose a liver segmentation with seven portal segments, which will result in unified criteria describing this organ.

DURAND, L. C. A. Anatomía del hígado (A05.8.01.001). Revisión mundial, 2019. Nuevos hallazgos, conceptos y definiciones respaldan una división del hígado en siete segmentos portales. Int. J. Morphol., 37(3):1179-1186, 2019.

RESUMEN: La confusión existente en la descripción de la anatomía del hígado humano nos llevó a realizar esta revisión a nivel mundial. Las investigaciones se centran en la vascularización 
Table IV. Liver anatomy and surgical resections.

\begin{tabular}{lcl}
\hline First order fractionation & $\begin{array}{c}\text { Denomination } \\
\text { of resection }\end{array}$ & \begin{tabular}{c} 
Parts of the liver \\
\hline
\end{tabular} \\
\hline
\end{tabular}

The hepatic part is the parenchyma irrigated by a primary branch of the portal vein; right branch irrigates the right part; left branch irrigates the left part.

When the segmental portal branch $\mathrm{V}$ emerges from the right portal, the main portal fissure of the liver divides the organ into a large right part and another smaller left part.
Right or left hepatectomy stipulating whether segment $I$ is included or not.
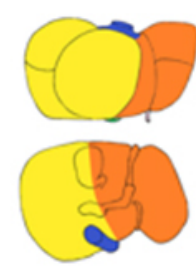

When the segmental portal branch $\mathrm{V}$ emerges from the left portal, the right portal fissure divides the organ into a small right part and another larger left part.

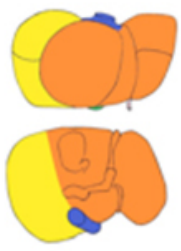

\begin{tabular}{lll}
\hline Second order fractionation & Resection & Liver Divisions
\end{tabular}

We call "Division" to the parenchyma among the vertical portal fissures of the liver. There are four divisions:

1. - The right lateral division (A05.8.01.049) located to the right of the right portal fissure contains portal segments VI and VII.

2. - The right medial division (A05.8.01.046) located between the right portal fissure and the main portal fissure contains portal segment $\mathrm{V}$, whose segmental branch can emerge from the right portal branch $(79 \%)$ or left portal branch (21\% of cases).

3. - The left medial division (A05.8.01.041) located between the main and umbilical portal fissures contains portal segment IV.

Segment $\mathrm{I}$ is contained in both medial divisions.

4. - The left lateral division (A05.8.01.038) located to the left of the umbilical fissure contains portal segments II and III.

\section{Third order fractionation}

The hepatic portal vein is divided into right and left branches, which emit seven terminal or segmental branches for seven portal segments.

Segmental branches I, II, III and IV emerge from the left portal branch and branches V, VI and VII emerge from the right portal $(79 \%)$; in $21 \%$, branches I, II, III, IV and V emerge from the left portal, and branches VI and VII from the right portal; everything happens inside the channel of the Porta hepatis. The segmental branch I is light blue, II in white, III in pink, IV in orange, $\mathrm{V}$ in yellow, VI in green and VII in brown.

Resection
Segmentectom
y
Adding ther Portal Segments
segment
number (s).


del hígado, el conocimiento obtenido mediante disecciones seriadas en embriones, fetos y adultos han aportado nuevos conocimientos que fundamentan nuevas definiciones. Investigadores de países distantes han coincidido en encontrar las bases para proponer una segmentación del hígado con siete segmentos portales.

tos portales.

PALABRAS CLAVE: Anatomía, Hígado; Siete segmen-

\section{REFERENCES}

Abdalla, E. K.; Vauthey, J. N. \& Couinaud, C. The caudate lobe of the liver: implications of embryology and anatomy for surgery. Surg. Oncol. Clin. N. Am., 11(4):835-48, 2002.

Alghamdi, T.; Viebahn, C.; Justinger, C. \& Lorf, T. Arterial Blood Supply of Liver Segment IV and Its Possible Surgical Consequences. Am. J. Transplant., 17(4):1064-70, 2017.

Bianchi, H. F.; Algieri, R. D.; Sanjurjo, D.; Ottone, N. E. \& Fuentes, R. Multiple anatomical variations of the hepatic pedicle. Case report and clinical application. Int. J. Morphol., 32(3):782-5, 2014.

Bismuth, H. A new look on liver anatomy: needs and means to go beyond the Couinaud scheme. J. Hepatol., 60(3):480-1, 2014.

Bismuth, H. Revisiting liver anatomy and terminology of hepatectomies. Ann. Surg., 257(3):383-6, 2013.

Botero, A. C. \& Strasberg, S. M. Division of the left hemiliver in man-segments, sectors, or sections. Liver Transpl. Surg., 4(3):226-31, 1998.

Bret, P. M.; de Stempel, J. V.; Atri, M.; Lough, J. O. \& Illescas, F. F. Intrahepatic bile duct and portal vein anatomy revisited. Radiology, 169(2):405-7, 1988.

Cantlie, J. On a new arrangement of the right and left lobes of the liver. $J$. Anat. Physiol., 32:4-9, 1898.

Castorina, S. Review of the nomenclature of the liver anatomical and functional areas by three-dimensional volume rendering 64-multislice computed tomography. Proposal for an update of the terminology. Ital. J. Anat. Embryol., 119(3):169-79, 2014.

Champetier, J.; Yver, R. \& Tomasella, T. Functional anatomy of the liver of the human fetus: applications to ultrasonography. Surg. Radiol. Anat., 11(1):53-62, 1989.

Chhabra, N.; Shrivastava, T.; Garg, L. \& Mishra, B. K. An anatomic variant caudate lobe in a cadaver. Int. J. Res. Med. Sci., 2(2):759-761, 2014

Couinaud, C. Liver anatomy: portal (and suprahepatic) or biliary segmentation. Dig. Surg., 16(6):459-67, 1999.

Couinaud, C. Liver lobes and segments: notes on the anatomical architecture and surgery of the liver. Presse Med., 62(33):709-12, 1954.

Dandekar, U.; Dandekar, K. \& Chavan, S. Right hepatic artery: a cadaver investigation and its clinical significance. Anat. Res. Int., 2015:412595, 2015.

Durand-López, C. A. \& Ramos-Serrano, D. Y. Seven segmental pedicles at the porta hepatis. Int. J. Morphol., 36(3):931-6, 2018.

Durand-López, C. A. Left part of the liver (A05.8.01.037). Int. J. Morphol., 36(1):113-20, 2018.

Durand-López, C. A. Liver: Seven hepatic segments. Int. J. Morphol., 34(4):1522-30, 2016.

Durand-López, C. A. Liver: the portal segment V. Int. J. Morphol., 35(1):363-7, 2017.

Durand-López, C. A.; Rázuri-Bustamante, C. R. \& Cervera-Carrillo, A. Liver: New Definitions and Proposals for SILAT-FCAT-IFAA. Int. $J$. Morphol., 36(2):651-4, 2018.

Durand-López, C. A.; Torres Girón, C. A. \& Cervera Carrillo, A. Hepatic portal segmentation using reconstructed three-dimensional tomography images. Int. J. Morphol., 35(3):859-63, 2017.

Durand, L. C. A. Hígado: Siete Segmentos Portales. Beau Bassin, Editorial Académica Española, 2017.
Fasel, J. H. \& Schenk, A. Concepts for liver segment classification: neither old ones nor new ones, but a comprehensive one. J. Clin. Imaging Sci., 3:48, 2013.

Fasel, J. H. Portal venous territories within the human liver: an anatomical reappraisal. Anat. Rec. (Hoboken), 291(6):636-42, 2008.

Fasel, J. H.; Majno, P. E. \& Peitgen, H. O. Liver segments: an anatomical rationale for explaining inconsistencies with Couinaud's eight-segment concept. Surg. Radiol. Anat., 32(8):761-5, 2010.

Fischer, L.; Cardenas, C.; Thorn, M.; Benner, A.; Grenacher, L.; Vetter, M.; Lehnert, T.; Klar, E.; Meinzer, H. P. \& Lamadé, W. Limits of Couinaud's liver segment classification: a quantitative computer-based three-dimensional analysis. J. Comput. Assist. Tomogr., 26(6):962-7, 2002.

Germain, T.; Favelier, S.; Cercueil, J. P.; Denys, A.; Krausé, D. \& Guiu, B. Liver segmentation: practical tips. Diagn. Interv. Imaging, 95(11):1003$16,2014$.

Glisson, F. Anatomia hepatis. Den Haag, Hagae-Comitum: A. Leers, 1681.

Healey, J. E. Jr. \& Schroy, P. C. Anatomy of the biliary ducts within the human liver; analysis of the prevailing pattern of branchings and the major variations of the biliary ducts. AMA Arch. Surg., 66(5):599-616, 1953.

Hikspoors, J. P. J. M.; Peeters, M. M. J. P.; Kruepunga, N.; Mekonen, H. K.; Mommen, G. M. C.; Köhler, S. E. \& Lamers, W. H. Human liver segments: role of cryptic liver lobes and vascular physiology in the development of liver veins and left-right asymmetry. Sci. Rep., 7(1):17109, 2017b.

Hikspoors, J. P. J. M.; Peeters, M. M. J. P.; Mekonen, H. K.; Kruepunga, N.; Mommen, G. M. C.; Cornillie, P.; Köhler, S. E. \& Lamers, W. H. The fate of the vitelline and umbilical veins during the development of the human liver. J. Anat., 231(5):718-35, 2017a.

Ibukuro, K.; Fukuda, H.; Tobe, K.; Akita, K. \& Takeguchi, T. The vascular anatomy of the ligaments of the liver: gross anatomy, imaging and clinical applications. Br. J. Radiol., 89(1964):20150925, 2016.

Iqbal, S.; Iqbal, R. \& Iqbal, F. Surgical Implications of Portal Vein Variations and Liver Segmentations: A Recent Update. J. Clin. Diagn. Res., 11(2):AE01-AE05, 2017.

Ishibashi, Y.; Sato, T. J.; Hirai, I.; Murakami, G.; Hata, F. \& Hirata, K. Ramification pattern and topographical relationship between the portal and hepatic veins in the left anatomical lobe of the human liver. Okajimas Folia Anat. Jpn., 78(2-3):75-82, 2001.

Joshi, M. M. \& Chavan, S. K. Morphological study of adult human cadaveric liver. Int. J. Anat. Res., 5(3.2):4284-9, 2017.

Kalaycı, T. Ö.; Kutlu, R.; Karasu, S. \& Yılmaz, S. Investigation of right lobe hepatic vein variations of donor using 64-detector computed tomography before living donor liver transplantation. Turk. J. Gastroenterol., 25 Suppl. 1:9-14, 2014.

Kawarada, Y.; Das, B. C. \& Taoka, H. Anatomy of the hepatic hilar area: the plate system. J. Hepatobiliary Pancreat. Surg., 7(6):580-6, 2000.

Kelly, P.; Fung, A.; Qu, J.; Greig, P.; Tait, G.; Jenkinson, J.; McGilvray, I. $\&$ Agur, A. Depicting surgical anatomy of the porta hepatis in living donor liver transplantation. J. Vis. Surg., 3:43, 2017.

Kimura, W.; Fukumoto, T.; Watanabe, T. \& Hirai, I. Variations in portal and hepatic vein branching of the liver. Yamagata Med. J., 33(2):115$21,2015$.

Li, X.; Xuesong, X. \& Jianping, G. Clinical significance of inferior right hepatic vein. Am. J. Med. Case Res., 4(1):26-30, 2016.

Majno, P.; Mentha, G.; Toso, C.; Morel, P.; Peitgen, H. O. \& Fasel, J. H. Anatomy of the liver: an outline with three levels of complexity--a further step towards tailored territorial liver resections. J. Hepatol. 60(3):654-62, 2014.

Marcos, A.; Ham, J. M.; Fisher, R. A.; Olzinski, A. T. \& Posner, M. P. Surgical management of anatomical variations of the right lobe in living donor liver transplantation. Ann. Surg., 231(6):824-31, 2000

McIndoe, A. H. \& Counseller, V. S. The bilaterality of the liver. Arch. Surg., 15(4):589-612, 1927

Mehare, T.; Bekele, A.; Getachew, A. \& Yigremali. Assessment of 
morphological variations and its specific location on the surface of adult human liver in Ethiopian cadavers University of Gondar, Bahir Dar University, Addis Ababa University, St. Paulos Medical School and Hawassa University, Ethiopia. Int. J. Med. Res. Health Sci., 6(10):121-9, 2017.

Mitidieri, V. \& Loccisano, M. Dorsal sector of the liver. Rev. Argent. Anat. Online, 5(2):54-62, 2014.

Patil, S.; Sethi, M. \& Kakar, S. Morphological study of human liver and its surgical importance. Int. J. Anat. Res., 2(2):310-4, 2014.

Pintado Luna, E. \& Durand, L. C. A. Segmentación hepática, bases anatómicas para las hepatectomías. Trib. Med. Int., (540), 1978.

Rex, H. Beiträge zur Morphologie der Sängerleber. Leipzig, Wilhelm Engelmann, Verlag, 1888.

Rieker, O.; Klos, G.; Beckmann, P.; Vomweg, T. W.; Otto, G. \& Thelen, M. Automatic classification of liver segments according to Couinaud: development of a new algorithm and evaluation spiral CT data. Rofo, 175(12):1655-9, 2003.

Rutkauskas, S.; Gedrimas, V.; Pundzius, J.; Barauskas, G. \& Basevicius, A. Clinical and anatomical basis for the classification of the structural parts of liver. Medicina (Kaunas), 42(2):98-106, 2006.

Sakamoto, Y.; Kokudo, N.; Kawaguchi, Y. \& Akita, K. Clinical anatomy of the liver: Review of the 19th Meeting of the Japanese Research Society of Clinical Anatomy. Liver Cancer, 6(2):146-60, 2017.

Shilal, P. \& Tuli, A. Anatomical variations in the pattern of the right hepatic veins draining the posterior segment of the right lobe of the liver. $J$. Clin. Diagn. Res., 9(3):AC08-12, 2015.

Soyer, P. Segmental anatomy of the liver: utility of a nomenclature accepted worldwide. AJR Am. J. Roentgenol., 161(3):572-3, 1993.

Sureka, B.; Patidar, Y.; Bansal, K.; Rajesh, S.; Agrawal, N. \& Arora, A. Portal vein variations in 1000 patients: surgical and radiological importance. Br. J. Radiol., 88(1055):20150326, 2015.

Tani, K.; Shindoh, J.; Akamatsu, N.; Arita, J.; Kaneko, J.; Sakamoto, Y.; Hasegawa, K. \& Kokudo, N. Venous drainage map of the liver for complex hepatobiliary surgery and liver transplantation. $H P B($ Oxford $)$, 18(12):1031-8, 2016.

Vellar, I. D. Preliminary study of the anatomy of the venous drainage of the intrahepatic and extrahepatic bile ducts and its relevance to the practice of hepatobiliary surgery. A. N. Z. J. Surg., 71(7):418-22, 2001.

Vernon, H. \& Kasi, A. Anatomy, Abdomen and Pelvis, Liver. In: StatPearls. Treasure Island (FL), StatPearls Publishing, 2019. Available from: https://www.ncbi.nlm.nih.gov/books/NBK500014/

Vinnakota, S. \& Jayasree, N. A new insight into the morphology of the human liver: a cadaveric study. ISRN Anat., 2013:689564, 2013.

Yan, J.; Tokunaga, K.; Takahashi, H. \& Hitomi, J. Multiple arteries supplying the human liver: A case report of a rare variation of the blood supplying pattern in a Japanese population. Edorium J. Anat. Embryol., 2:1-5, 2015.

Zheng, W.; Zi-Hai, D.; Jie, Z.; Shi-Zhen, Z.; Jian-Hua, L. \& Yi-Xiong, L. Anatomy of the retrohepatic tunnel in a Chinese population and its clinical application in liver surgery. Sci. Rep., 7:44977, 2017.

\author{
Corresponding author: \\ Dr. César Durand \\ Universidad Ricardo Palma \\ Lima \\ PERU
}

\section{Email:cesaraugusto@gmail.com}

Received: 25-09-2018

Accepted: 14-01-2019 